\title{
Activation of bovine somatic cell nuclear transfer embryos by PLCZ cRNA injection
}

\author{
Pablo J Ross ${ }^{1}$, Ramon M Rodriguez ${ }^{1}$, Amy E lager ${ }^{1}$, Zeki Beyhan ${ }^{1}$, Kai Wang ${ }^{1}$, Neli P Ragina ${ }^{1}$, \\ Sook-Young Yoon ${ }^{2}$, Rafael A Fissore ${ }^{2}$ and Jose B Cibelli ${ }^{1,3,4}$ \\ ${ }^{1}$ Department of Animal Science, Michigan State University, East Lansing, Michigan 48824, USA, ${ }^{2}$ Department of \\ Veterinary and Animal Sciences, University of Massachusetts, Amherst, Massachusetts 01003, USA, ${ }^{3}$ Department of \\ Physiology, Michigan State University, East Lansing, Michigan 48824, USA and ${ }^{4}$ Programa Andaluz de Terapia Celular \\ y Medicina Regenerativa, 41092 Andalucía, Spain
}

Correspondence should be addressed to J B Cibelli; Email: cibelli@msu.edu

\begin{abstract}
The production of cloned animals by the transfer of a differentiated somatic cell into an enucleated oocyte circumvents fertilization. During fertilization, the sperm delivers a sperm-specific phospholipase C (PLCZ) that is responsible for triggering $\mathrm{Ca}^{2+}$ oscillations and oocyte activation. During bovine somatic cell nuclear transfer (SCNT), oocyte activation is artificially achieved by combined chemical treatments that induce a monotonic rise in intracellular $\mathrm{Ca}^{2+}$ and inhibit either phosphorylation or protein synthesis. In this study, we tested the hypothesis that activation of bovine nuclear transfer embryos by PLCZ improves nuclear reprogramming. Injection of PLCZ cRNA into bovine SCNT units induced $\mathrm{Ca}^{2+}$ oscillations similar to those observed after fertilization and supported high rates of blastocyst development similar to that seen in embryos produced by IVF. Furthermore, gene expression analysis at the eight-cell and blastocyst stages revealed a similar expression pattern for a number of genes in both groups of embryos. Lastly, levels of trimethylated lysine 27 at histone $\mathrm{H} 3$ in blastocysts were higher in bovine nuclear transfer embryos activated using cycloheximide and 6-dimethylaminopurine (DMAP) than in those activated using PLCZ or derived from IVF. These results demonstrate that exogenous PLCZ can be used to activate bovine SCNT-derived embryos and support the hypothesis that a fertilization-like activation response can enhance some aspects of nuclear reprogramming. Reproduction (2009) 137 427-437
\end{abstract}

\section{Introduction}

The generation of live offspring after somatic cell nuclear transfer (SCNT) has been successfully achieved in numerous mammalian species (Cibelli 2007). However, the overall efficiency of the technology remains extremely low (Wilmut et al. 2002). Failure to correctly reprogram the somatic cell genome following transfer into the oocyte cytoplasm has been hypothesized to be a major cause of developmental abnormalities (Shi et al. 2003, Hochedlinger \& Jaenisch 2006). Nuclear reprogramming - the process by which a specialized nucleus reacquires developmental potential, adopting the role of a zygotic nucleus - involves silencing somatic-specific genes and activating essential embryonic genes (Latham 2005). Although the process of nuclear reprogramming is not fully understood, it is becoming evident that epigenetic modifications of chromatin (e.g. methylation and/or acetylation of DNA and histones) are fundamental for the regulation of gene expression (Reik et al. 2001, Rideout et al. 2001).

In most mammalian species, oocytes are ovulated at the MII stage of meiosis and remain arrested until fertilized by sperm. Initiation of development is triggered by a series of long-lasting oscillations of intracellular free calcium $\left(\left[\mathrm{Ca}^{2+}\right]_{\mathrm{i}}\right)$. Several pieces of evidence support the hypothesis that the sperm, upon fusion with the oocyte, delivers a sperm-specific isoform of phospholipase C (PLCZ; Saunders et al. 2002, Kurokawa et al. 2004, Swann et al. 2004, 2006, Knott et al. 2005, Malcuit et al. 2006a). PLCZ has the ability to function at basal $\mathrm{Ca}^{2+}$ concentrations (Kouchi et al. 2004) and thus, upon entering the oocyte's cytoplasm, induces hydrolysis of phosphatidylinositol-4, 5-bisphosphate ( $\left.\mathrm{PIP}_{2}\right)$, generating 1, 2-diacylglycerol (DAG), and $I P_{3}$. In turn, $I P_{3}$ binds to its receptor $\left(I P_{3} R\right)$, located on the endoplasmic reticulum membrane, and induces a conformational change that allows release of $\mathrm{Ca}^{2+}$ into the oocyte's cytoplasm. By an as yet uncharacterized mechanism, $\mathrm{Ca}^{2+}$ release and uptake are repeated, generating what is described as $\left[\mathrm{Ca}^{2+}\right]_{\mathrm{i}}$ oscillations. The pattern of $\left[\mathrm{Ca}^{2+}\right]_{i}$ oscillations at fertilization is species specific, and these oscillations have been observed to occur over a relatively long period of time ( 3 to $4 \mathrm{~h}$ in mice; $16-18 \mathrm{~h}$ in cattle). 
The significance of the $\left[\mathrm{Ca}^{2+}\right]_{i}$ oscillatory pattern has been well studied in mice and rabbits (Ozil \& Huneau 2001, Ducibella et al. 2006). Alterations in oocyte calcium signaling affected not only the early events of embryonic development (Ducibella et al. 2002, Ozil et al. 2005), but also gene expression in eight cell (Rogers et al. 2006) and blastocyst-stage embryos (Ozil et al. 2006), implantation (Ozil \& Huneau 2001, Ozil et al. 2006), and even development to term (Ozil et al. 2006). It is possible that the long-lasting effect of $\left[\mathrm{Ca}^{2+}\right]_{i}$ oscillations was mediated by alterations in chromatin structure and reprogramming of gene expression occurring after fertilization (Ozil \& Huneau 2001, Ozil et al. 2006, Rogers et al. 2006). These observations suggest that improper oocyte activation may affect the level of nuclear reprogramming following SCNT.

Most activation protocols commonly used during SCNT rely on chemicals that not only induce a nonphysiological $\mathrm{Ca}^{2+}$ transient pattern, but also affect other cellular processes, with possible negative consequences for embryonic development (Alberio et al. 2001a, $2001 b)$. For example, the use of cycloheximide (CHX) during activation of bovine SCNTembryos was associated with delayed DNA synthesis (Alberio et al. 2001b), and the use of 6-dimethylaminopurine (DMAP) as the activating agent often resulted in a high proportion of aneuploid embryos (Winger et al. 1997, Van De Velde et al. 1999, Bhak et al. 2006).

We have previously shown that PLCZ cRNA injection into bovine oocytes was able to induce long-lasting $\left[\mathrm{Ca}^{2+}\right]_{i}$ oscillations and $\mathrm{IP}_{3} \mathrm{R}-1$ downregulation and that it supported high rates of parthenogenetic development to the blastocyst stage (Malcuit et al. 2006b, Ross et al. $2008 b)$. In the present study, we compared in vitro development, gene expression patterns, and epigenetic modifications in SCNT embryos activated by PLCZ CRNA injection with embryos activated by chemical methods or produced by IVF. Although all activation protocols supported oocyte activation and embryo development, embryos activated by PLCZ displayed gene expression profiles and levels of trimethylated lysine 27 at histone $\mathrm{H} 3(\mathrm{H} 3 \mathrm{~K} 27 \mathrm{me} 3)$ that closely resembled those seen in IVF embryos.

\section{Results \\ PLCZ triggers fertilization-like $\left[\mathrm{Ca}^{2+}\right]_{i}$ oscillations in bovine oocytes reconstructed by SCNT}

We have previously shown that injection of PLCZ cRNA into bovine oocytes induced long-lasting $\left[\mathrm{Ca}^{2+}\right]_{i}$ oscillations, downregulated $\mathrm{IP}_{3} \mathrm{R}-1$, and supported parthenogenetic development to the blastocyst stage (Malcuit et al. 2006b, Ross et al. 2008b). In the present study, we extended these findings and confirmed that PLCZ CRNA injection triggers fertilization-like $\left[\mathrm{Ca}^{2+}\right]_{i}$ oscillations in oocytes reconstructed by SCNT (Fig. 1). During the first $3 \mathrm{~h}$ after injection, a series of $\left[\mathrm{Ca}^{2+}\right]_{i}$ oscillations were observed with intervals of $28 \mathrm{~min}$, and then their frequency increased to one oscillation every $8 \mathrm{~min}$ from 5 to $9 \mathrm{~h}$ after PLCZ injection (Table 1). Some oocytes (5 out of 10) stopped oscillating during the recorded period at 9, 10.5, 11, 12, and $13 \mathrm{~h}$ after PLCZ injection. For those in which oscillations continued, the frequency started to decrease, with oscillations occurring every $26 \mathrm{~min}$ from 11 to $14 \mathrm{~h}$ post-activation.

The ability to induce repetitive $\left[\mathrm{Ca}^{2+}\right]_{i}$ rises by PLCZ cRNA injection provided a method to mimic the sperminduced oocyte activation stimulus and to test the hypothesis that a more physiological oocyte activation stimulus can improve reprogramming after SCNT.

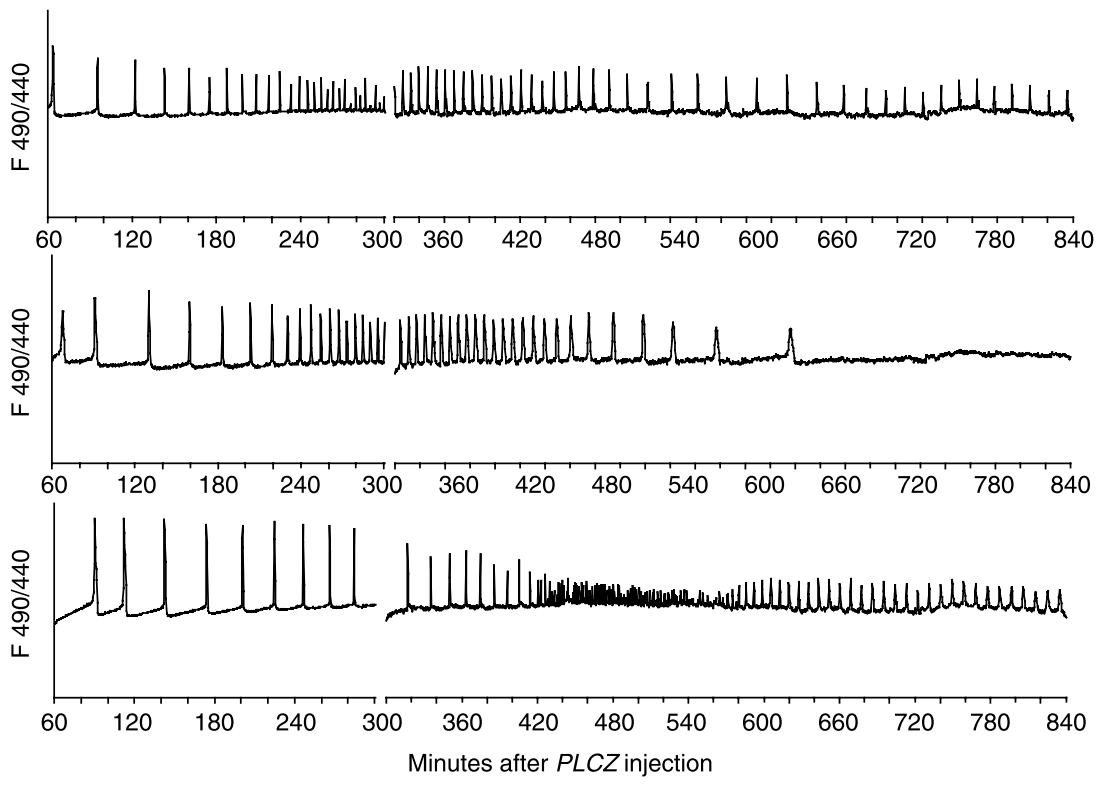

Figure 1 Representative $\left[\mathrm{Ca}^{2+}\right]_{\mathrm{i}}$ profiles observed in SCNT embryos from 1 to $14 \mathrm{~h}$ after murine PLCZ cRNA injection. 
Table 1 Time interval between $\left[\mathrm{Ca}^{2+}\right]_{i}$ oscillations in SCNT embryos activated using PLCZ cRNA injection.

\begin{tabular}{lcc}
\hline $\begin{array}{l}\text { Time after PLCZ } \\
\text { injection }(\mathrm{h})\end{array}$ & $\begin{array}{c}\text { Oscillating oocytes } \\
(\boldsymbol{n})\end{array}$ & $\begin{array}{c}\text { Mean } \pm \text { s.E.M. interval } \\
\text { between }\left[\mathbf{C a}^{\mathbf{2}}\right]_{\mathbf{i}} \\
\text { increases }(\mathrm{min})\end{array}$ \\
\hline 1 to 3 & $10 / 10$ & $28.4 \pm 1.6$ \\
3 to 5 & $10 / 10$ & $13.2 \pm 2.6$ \\
5 to 7 & $10 / 10$ & $8.1 \pm 1.3$ \\
7 to 9 & $10 / 10$ & $8.1 \pm 2.1$ \\
9 to 11 & $9 / 10$ & $19.8 \pm 5.3$ \\
11 to 14 & $5 / 10$ & $25.7 \pm 6.3$ \\
\hline
\end{tabular}

\section{Embryonic development of cloned embryos activated by PLCZ cRNA injection}

To evaluate whether PLCZ cRNA injection supports activation and in vitro development of bovine SCNT embryos, we injected mPLCZ cRNA into oocytes reconstructed by nuclear transfer and compared cleavage and development rates induced by this treatment with those induced by chemical activation and by IVF. Table 2 presents the results, and representative figures of blastocysts obtained with the different activation protocols are shown in Fig. 2. A total of 769 bovine SCNT embryos were produced in nine replicates. Equivalent cleavage rates, ranging from 75.4 to $79.2 \%(P>0.05)$, were observed among SCNT groups. The cleavage rate $(87.0 \%)$ of IVF embryos was higher than that of SCNT embryos $(P<0.05)$. Development of the embryos to blastocyst stage was the highest for SCNT embryos activated with ionomycin/CHX and the lowest for embryos produced by IVF $(P<0.05)$.

As indicators of embryo quality, we determined the total number of cells and their allocation to the inner cell mass (ICM) and trophectoderm (TE) of expanded/ hatched blastocysts. No differences were observed in total, TE or ICM cell numbers (Fig. 3a and c); however, the ratio of ICM:TE cells was higher in SCNT embryos activated using DMAP than in those activated using $\mathrm{CHX}$ or derived from IVF $(P<0.05)$. PLCZ-activated embryos did not differ from IVF or SCNT groups.

We also determined the incidence of apoptosis among blastocysts produced with the different activation strategies. The proportion of apoptotic cells in blastocysts, as assessed by TUNEL staining, was similar among all of the groups analyzed ( $P>0.05$; Fig. $3 a$ and $b)$.

Table 2 Preimplantation development of IVF- and SCNT-derived embryos activated using different protocols.

\begin{tabular}{llll}
\hline Treatment & $\begin{array}{l}\text { Embryos } \\
\text { cultured }\end{array}$ & \multicolumn{1}{c}{ Cleaved $(\%)$} & Blastocysts $(\%)$ \\
\hline IVF & 492 & $428(87.0)^{\mathrm{a}}$ & $125(25.4)^{\mathrm{a}}$ \\
$\mathrm{PLCZ}$ & 332 & $262(78.9)^{\mathrm{b}}$ & $92(27.7)^{\mathrm{a}, \mathrm{b}}$ \\
lono/DMAP & 327 & $259(79.2)^{\mathrm{b}}$ & $109(33.3)^{\mathrm{b}, \mathrm{c}}$ \\
lono/CHX & 329 & $248(75.4)^{\mathrm{b}}$ & $118(35.9)^{\mathrm{c}}$ \\
\hline
\end{tabular}

$\mathrm{a}, \mathrm{b}, \mathrm{c}$ Percentages not sharing a common letter are statistically different $\left(P<0.05, \chi^{2}\right.$-test $)$.
Finally, we performed chromosomal analysis at the blastocyst stage, since maintenance of normal ploidy is a prerequisite for embryos to develop to term. The fibroblast donor cell line used in this study had a normal diploid chromosomal composition. After SCNT, we observed that $86 \%$ of the embryos were diploid at the blastocyst stage irrespective of the activation protocol and were similar to IVF-derived embryos (Table 3).

Taken together, these results indicate that PLCZ cRNA injection was an effective method to induce activation of embryonic development after SCNT and that the embryos generated by this method presented similar characteristics to embryos produced by IVF in terms of cell number and allocation, apoptosis and embryo ploidy.

\section{Effect of oocyte activation method on gene expression at 8-cell and blastocyst stages}

Reprogramming of gene expression involves reactivation of important embryonic genes as well as the repression of somatic cell-specific genes. To test whether the type of activation stimulus affects the reactivation of embryonic genes, we first evaluated the abundance of transcripts at the eight-cell stage, which is the earliest stage where embryonic genome activation can be consistently assessed in bovine embryos. The expression levels of these transcripts were normalized to an external control to account for differences in RNA extraction and RT efficiency.

Gene expression analysis at the eight-cell stage revealed that cloned embryos were able to express desmocollin 2 (DSC2) and glucose transporter 1 (GLUT1) at levels similar to IVF embryos $(P>0.05$; Fig. 4), although GLUT1 expression was affected by the type of SCNT activation protocol, with embryos activated using $\mathrm{CHX}$ presenting a higher level of transcripts than those activated by PLCZ cRNA injection $(P<0.05)$. On the other hand, POU5F1 (Oct-3, OCT4) transcript abundance was significantly lower in DMAPactivated SCNT embryos than in IVF-derived embryos.

We also performed gene expression analysis at the blastocyst stage to evaluate expression of genes that are characteristic of the two cell lineages that comprise the blastocyst. POU5F1, NANOG, and SOX2 have been characterized as important for pluripotency and ICM formation, while the transcription factor CDX2 and the FGF receptor type 2 (FGFR2) have been shown to be expressed specifically in the TE of mouse embryos. We also determined the expression of TRYP 8 , a gene expressed by somatic cells but not during pre-implantation development of fertilized embryos, and of U2AF1L2, a gene that in a previous study (Beyhan et al. 2007) we found discriminated between IVF and SCNT embryos. Blastocyst gene expression was normalized to the exogenous control and then to the total cell number in the embryo, as determined just 


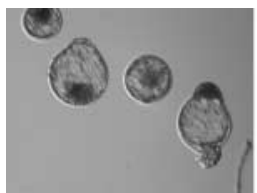

IVF

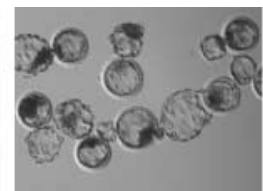

PLCZ

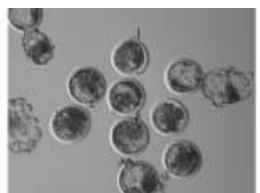

Lono/DMAP

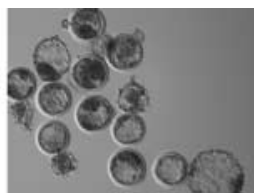

Lono/CHX
Figure 2 Representative pictures of blastocysts generated by IVF and SCNT using different activation protocols. before embryo lysis. We found that GAPDH, POU5F1, and $C D X 2$ were expressed at significantly lower levels in $\mathrm{CHX}$-activated SCNT embryos than in the other groups (Fig. 5). U2AF1L2, a gene involved in RNA splicing, was only detected in IVF embryos. Finally, TRYP8 that was expressed at high levels in the donor cells, was amplified in a higher proportion $(P<0.05)$ of SCNT embryos activated by CHX and DMAP (60 and $62.5 \%$ respectively) than in IVF and SCNT embryos activated using PLCZ (11 and 33\% respectively).

\section{Chromatin modifications in embryos produced by IVF or SCNT and activated by different means}

Although, the precise mechanism of nuclear reprogramming after SCNT has not been elucidated, chromatin remodeling is known to play a fundamental role. Chromatin remodeling involves, among other modifications, changes in acetylation and methylation of histone tails. In the present study, we used immunofluorescence to evaluate genome-wide histone methylation at histone $\mathrm{H} 3$ lysine 27, a change that is associated with gene silencing and histone acetylation at histone $\mathrm{H} 4$ lysine 5, a modification that is associated with transcriptional activation (Fig. 6). We found that the levels of acetylated histone did not differ among groups (Fig. 6b); however, the levels of H3K27me3 were higher in bovine SCNT embryos activated using $\mathrm{CHX}$ or DMAP compared with those activated using PLCZ or derived from IVF $(P<0.05$; Fig. 6c).

\section{Discussion}

SCNT remains an inefficient technique in spite of almost 10 years of research since the first mammal was cloned (Cibelli 2007). This inefficiency is commonly attributed to incomplete reprogramming of the somatic cell nucleus (Reik et al. 2001, Rideout et al. 2001, Latham 2004, Cibelli et al. 2006). Nuclear reprogramming is initiated by the recipient oocyte and likely continues through early embryonic development (Latham 2004). Oocyte activation may influence the reprogramming ability of the oocyte. Alterations of the signaling mechanism leading to oocyte activation and initiation

(a)
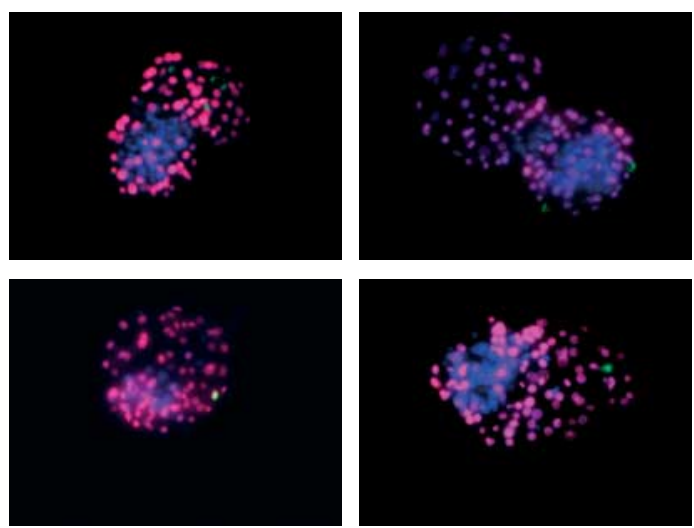

(b)

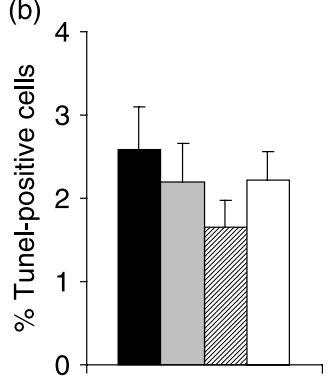

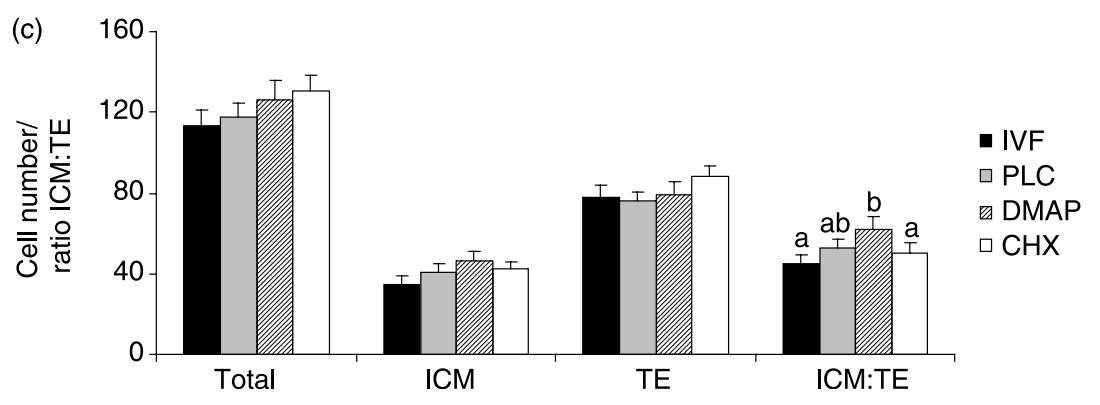

Figure 3 Cell number, allocation, and apoptosis in IVF and SCNT embryos produced using different activation methods. (a) Representative images of analyzed embryos; ICM (blue), TE (red), and TUNEL-positive nuclei (green). (b) Quantification of TUNEL-positive cells per embryo. (c) Comparison of cell number and allocation among groups. $\mathrm{a}, \mathrm{b}$ : bars not sharing a common letter are statistically different $(P<0.05)$. 
Table 3 Chromosomal composition of blastocysts activated using different protocols.

\begin{tabular}{lccccc}
\hline Treatment & $\boldsymbol{n}$ & Diploid & Tetraploid & Mixoploid & Total abnormal \\
\hline IVF & 15 & 13 & 2 & $13 \%$ & $2(13.3 \%)$ \\
PLCZ & 12 & 10 & 1 & $1^{\mathrm{a}}$ & $1(16.7 \%)$ \\
lono/DMAP & 12 & 11 & 1 & $1^{\mathrm{b}}$ & $3(15.0 \%)$ \\
lono/CHX & 20 & 17 & 2 & & \\
\hline
\end{tabular}

${ }^{\mathrm{a}}$ Diploid/triploid. ${ }^{\mathrm{b}}$ Diploid/tetraploid.

of embryonic development was shown to affect early events of oocyte activation - like mRNA translation (Ducibella et al. 2002, 2006) - as well as fetal and term development (Ozil et al. 2006), probably by affecting the reprogramming of the zygotic genome. In all mammals studied so far, oocyte activation is characterized by longlasting $\left[\mathrm{Ca}^{2+}\right]_{i}$ oscillations, which persist for several hours (Malcuit et al. 2006a). During bovine SCNT, oocytes are usually activated using chemicals that induce a single increase in $\left[\mathrm{Ca}^{2+}\right]_{\mathrm{i}}$, supplemented with broad-spectrum protein synthesis inhibitors or kinase inhibitors (Alberio et al. 2001a, Machaty 2006, Malcuit \& Fissore 2007). These treatments that do not recapitulate the signaling events triggered by the fertilizing sperm may have adverse consequences for nuclear reprogramming and for the development of cloned embryos (Alberio et al. 2001a, Malcuit \& Fissore 2007). We hypothesized that activating bovine SCNT embryos with a system that closely mimics the activation mechanism brought about by the sperm would result in a more efficient nuclear reprogramming. To address this hypothesis, we implemented a sperm-like activation protocol to induce activation of SCNT embryos.

PLCZ that has been characterized in mice (Saunders et al. 2002), humans (Rogers et al. 2004), pigs (Yoneda et al. 2006), and cattle (Ross et al. 2008b), is believed to be the activation factor that the sperm delivers upon fusion with the oocyte at fertilization. After injecting mPLCZ cRNA into SCNT-reconstructed bovine embryos, we observed long lasting $\left[\mathrm{Ca}^{2+}\right]_{i}$ oscillations similar to those elicited by fertilization (Fissore et al. 1992, Nakada et al. 1995); however, the increased frequency of $\left[\mathrm{Ca}^{2+}\right]_{\mathrm{i}}$ oscillations seen in SCNT embryos between 5 and $9 \mathrm{~h}$ after PLCZ injection was not observed after IVF; which likely reflects protein accumulation with increased

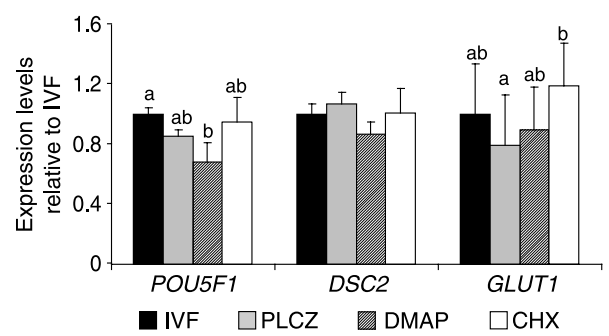

Figure 4 Quantification of mRNA abundance in eight-cell embryos generated by IVF or SCNT using different activation protocols. ${ }^{\mathrm{a}, \mathrm{b}}$ : bars not sharing a common letter are statistically different $(P<0.05)$. translation time. Along with our previous observations - that PLCZ CRNA injection into MIl oocytes induced $\left[\mathrm{Ca}^{2+}\right]_{i}$ oscillations, IP ${ }_{3} \mathrm{R}-1$ downregulation, and parthenogenetic development (Ross et al. 2008b) - these data suggest that injection of PLCZ cRNA into oocytes reconstructed by SCNT can be used as an activation stimulus that mimics sperm-induced activation.

PLCZ was effective at inducing pre-implantation development of SCNT embryos, which did not seem to be affected by the type of activation stimulus. SCNT embryos activated by PLCZ cRNA injection or common chemical activation stimuli (ionomycin/DMAP and ionomycin/CHX) produced blastocysts at rates of 25 to $36 \%$, which are comparable with those reported in the literature for IVF and SCNT embryos (Cibelli et al. 1998, Zakhartchenko et al. 1999, Heyman et al. 2002, Kane 2003). Total cell number and number of cells allocated to the TE and ICM have been regarded as valuable indicators of cattle embryo quality (van Soom et al. 1997, 2001). A higher total cell number in the embryo correlated with IVF (van Soom et al. 1997) and SCNT embryos' developmental potential (Renard et al. 2007). Moreover, it has been suggested that aberrant allocation of ICM and TE cells to the blastocyst stage may be responsible for the abnormalities observed after transfer of SCNT embryos (Koo et al. 2002). Like other observers, we found that SCNT embryos activated using ionomycin/ DMAP presented a significantly higher ratio of ICM:total cells when compared with IVF and in vivo-produced embryos (Koo et al. 2002). On the other hand, we saw no differences between embryos activated using ionomycin/ $\mathrm{CHX}$ or PLCZ cRNA injection and IVF controls, which

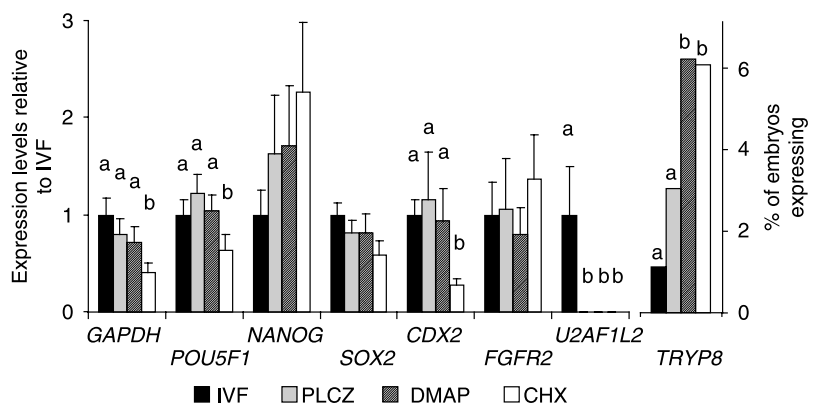

Figure 5 Quantification of mRNA abundance in blastocysts generated by IVF or SCNT using different activation protocols. ${ }^{\text {a,b }}$ : bars with different superscripts differ significantly $(P<0.05)$. 
(a)

DNA

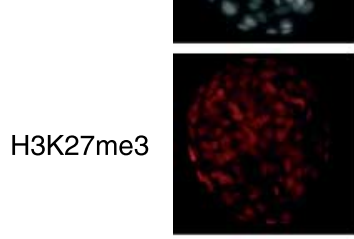

H4K5Ac

(b)

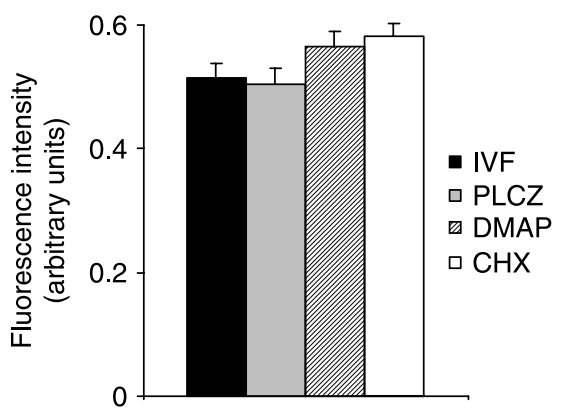

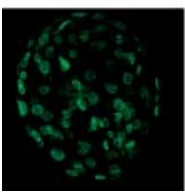

\begin{abstract}
IVF
\end{abstract}
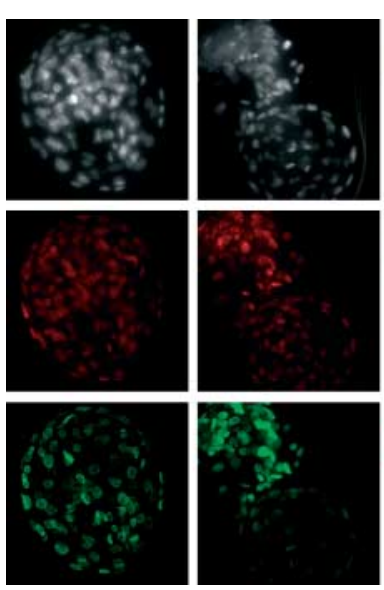
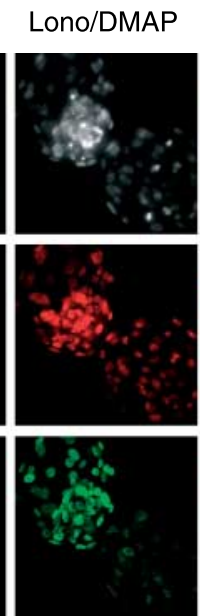

Lono/CHX

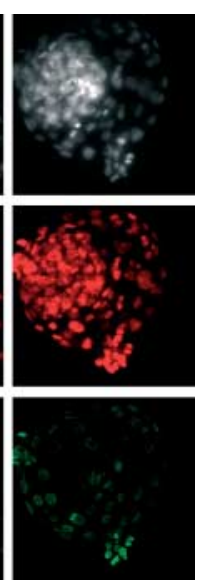

(c)

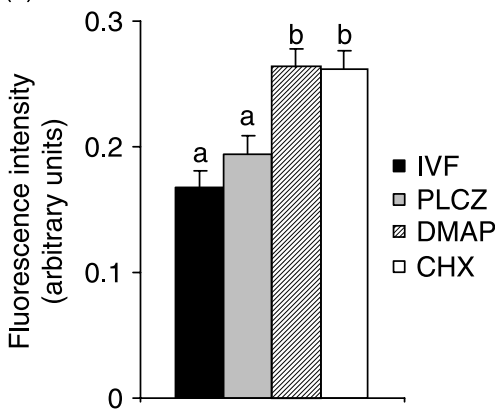

Figure 6 Histone methylation and acetylation analysis of IVF and SCNT embryos activated using different protocols. (a) Representative pictures of immunostained blastocyst-stage embryos. (b) Semiquantitative evaluation of $\mathrm{H} 4 \mathrm{~K} 5 \mathrm{Ac}$ and (c) H3K27me3 immunostaining. $\mathrm{a}, \mathrm{b}$ : bars with different superscripts differ significantly $(P<0.05)$. suggests that activating SCNT embryos by these means may improve their developmental potential.

When we looked at reactivation of embryonic genes in cloned embryos, PLCZ presented a similar pattern of gene expression to IVF controls, while ionomicin/CHXand ionomicin/DMAP-activated embryos showed some differences compared with IVF embryos. For example, a housekeeping gene $(G A P D H)$, a transcription factor important for ICM development (POU5F1), and a transcription factor important for TE development (CDX2) were expressed at lower levels in SCNT embryos activated by ionomycin/CHX compared with the other groups. These abnormalities in gene expression were in all cases observed for only one of the chemical treatments. This led us to speculate that they were a consequence of the inhibition of protein synthesis (CHX) or protein phosphorylation (DMAP), but not because of the abnormal $\left[\mathrm{Ca}^{2+}\right]_{i}$ regimen. On the other hand, in agreement with our previous report (Beyhan et al. 2007), U2AF1L2, a gene involved in RNA splicing, was only detected in IVF embryos, indicating that reprogramming of this locus failed in SCNT embryos irrespective of the activation protocol. Although the role of U2AF1L2 in embryonic development has not been investigated, the intrinsic capacity of this gene to affect several cellular processes could lead to potentially serious alterations in the ability of cloned embryos to develop normally. Furthermore, this suggests that some abnormalities associated with SCNT are not improved by activation with PLCZ.

Activation with PLCZ required treatment with cytochalasin $\mathrm{B}(\mathrm{CB})$ to avoid the segregation of a second polar body containing part of the somatic cell chromosomes (Supplementary Figure 1, which can be viewed online at www.reproduction-online.org/supplemental/). $\mathrm{CB}$ is an actin-polymerization inhibitor that may detrimentally affect embryonic development or nuclear reprogramming by not allowing the movement of intracellular molecules to their required sites of action. Also, a different $\left[\mathrm{Ca}^{2+}\right]_{i}$ oscillatory pattern may be necessary to induce reprogramming of a somatic cell nucleus rather than to reprogram the gametes' chromatin, e.g., during fertilization. Moreover, other components of the sperm that are not provided by the somatic cell may be required to initiate normal embryonic development. For instance, the sperm protein PAWP (WBP2NL) that resides in the perinuclear theca was found to be required for meiotic resumption and pronuclear development following fertilization $(\mathrm{Wu}$ et al. 2007). Also, mature sperm carried full length mRNAs that were delivered into the oocyte upon fertilization, giving credence to the notion that they may indeed play 
a role in development (Ostermeier et al. 2004); however, the functional relevance of these molecules to fertilization and embryonic development has not yet been determined (Krawetz 2005). Testing the need for these sperm components in SCNT models will provide information about their function, as well as potentially improving cloning efficiency.

Expression of donor-cell-specific genes was previously observed in cloned mice, suggesting that nuclear reprogramming may be incomplete after nuclear transfer (Gao et al. 2003). This epigenetic memory can have adverse consequences for embryonic development, as demonstrated by mouse cloning experiments in which nuclear transfer embryos developed better in donor cell culture medium than in embryo culture medium (Gao et al. 2003). We observed that a somatic-specific gene (TRYP8) was inactivated more efficiently in PLCZactivated embryos than in the chemically-activated embryos. Our finding that a more physiological activation stimulus (PLCZ) resulted in a reduction of somatic gene expression abnormalities provides evidence that oocyte activation may play a role in reprogramming the embryonic genome, leading to erasure of somatic cell epigenetic memory. Similarly, it was shown that a more-physiological pattern of $\left[\mathrm{Ca}^{2+}\right]_{i}$ oscillations affected gene expression at the blastocyst stage (Ozil et al. 2006) and that an appropriate level of $\mathrm{Ca}^{2+}$ signal was required to induce translation of maternally stored mRNA in the early zygote (Ducibella et al. 2002), potentially affecting the reprogramming of the zygotic chromatin.

Trimethylation of histone $\mathrm{H} 3$ at lysine 27 is catalyzed by polycomb group complexes and is associated with stable and heritable gene silencing (Schuettengruber et al. 2007). In the present study, we found that levels of H3K27me3 in SCNT embryos were similar to IVF embryos when they were activated by a sperm-like stimulus (PLCZ) but higher when chemical activation methods were used. This observation agreed with our gene expression data, where chemically activated embryos showed higher levels of somatic gene expression, suggesting that embryos activated by chemical means may retain a somatic-like pattern of epigenetic arrangement compared with PLCZ-activated and fertilized embryos. The mechanism by which the activation system influenced the reprogramming of H3K27me3 represents an interesting area for future research. Moreover, given the importance of H3K27me3 in conferring stem cell identity to embryonic stem cells (Azuara et al. 2006, Boyer et al. 2006, Lee et al. 2006), it is tempting to speculate that aberrant $\mathrm{H} 3 \mathrm{~K} 27 \mathrm{me} 3$, in cloned embryos activated by chemical means, may lead to abnormal cell differentiation, thus resulting in developmental abnormalities and embryonic lethality.

In summary, we have utilized an oocyte activation treatment (PLCZ cRNA injection) that closely recapitulated the calcium oscillation patterns observed after fertilization. This treatment supported activation and in vitro development of bovine SCNT embryos at rates comparable with those induced by chemical activation and by fertilization. Also, embryos activated using this protocol had similar characteristics - in terms of cell number, ploidy, apoptosis, and chromatin modifications - to in vitro fertilized embryos. Moreover, our experiments provide evidence that the oocyte activation system chosen can, at the eight-cell and blastocyst stages, affect gene expression as well as chromatin modifications, implying that the activation stimulus has a role in nuclear reprogramming. Conversely, U2AF1L1 expression was not detected in any of the SCNT groups, indicating that some abnormalities common to SCNT embryos persisted in clones activated by PLCZ cRNA injection. Allowing SCNT embryos activated with PLCZ to develop to further stages, and even to term, will likely provide more conclusive evidence on the involvement of the activation stimulus during nuclear reprogramming.

\section{Materials and Methods}

All chemicals were purchased from Sigma unless stated otherwise.

\section{PLCZ cRNA preparation}

A pBluescript vector containing the full-length coding sequence of murine PLCZ (mPLCZ) was linearized with EcoR1 and used as a template for in vitro transcription by the T7 mMESSAGE mMACHINE High Yield Capped RNA Transcription Kit (Ambion, Austin, TX, USA), following the manufacturer's instructions. A poly $(\mathrm{A})$ tail was then added to the cRNA using a Poly(A) Tailing Kit (Ambion). The cRNA was purified using the MEGAclear Kit (Ambion) and stored at $-80{ }^{\circ} \mathrm{C}$ in single-use aliquots. Just before use, the cRNA was thawed on ice, heated to $85^{\circ} \mathrm{C}$ for $3 \mathrm{~min}$, and centrifuged at $16000 \mathrm{~g}$ at $4{ }^{\circ} \mathrm{C}$ for $5 \mathrm{~min}$.

\section{Somatic cell nuclear transfer}

Oocytes were obtained from abattoir-derived ovaries and matured in vitro as previously described (Ross et al. 2006). SCNT was performed as described (Ross et al. 2006). Briefly, cumulus cells were removed by vortex agitation in media containing $1 \mathrm{mg} / \mathrm{ml}$ hyaluronidase $16-18 \mathrm{~h}$ after oocyte maturation. Oocyte enucleation was performed by aspirating the metaphase II chromosomes in a small volume of surrounding cytoplasm. Donor cells were dissociated by treatment with $10 \mathrm{IU} / \mathrm{ml}$ of pronase in HECM-Hepes $(\mathrm{HH})$ media (Seshagiri \& Bavister 1989) for $5 \mathrm{~min}$. A single cell was inserted into the perivitelline space of the enucleated oocyte and fused in calcium-free sorbitol fusion medium by applying a single direct current pulse of 234 volts $/ \mathrm{mm}$ for $22 \mu \mathrm{s}$. 


\section{Activation and embryo culture}

Activation of fused nuclear transfer units (NTUs) was performed $2 \mathrm{~h}$ after fusion. Three different activation protocols were implemented: 1) ionomycin/DMAP, 2) ionomycin/CHX, and 3) PLCZ. In groups 1 and 2, NTUs were treated with $5 \mu \mathrm{M}$ ionomycin (Calbiochem, San Diego, CA, USA) for $4 \mathrm{~min}$, followed by incubation in potassium simplex optimized medium (KSOM) medium containing either $10 \mu \mathrm{g} / \mathrm{ml} \mathrm{CHX}$ and $5 \mu \mathrm{g} / \mathrm{ml} \mathrm{CB}$ for $5 \mathrm{~h}$ (ionomycin/CHX), or $2 \mathrm{mM} \mathrm{DMAP}$ for $4 \mathrm{~h}$ (ionomycin/DMAP). Activation using PLCZ was performed by intracytoplasmic injection of $\sim 6$ to $8 \mathrm{pl}$ of $1 \mu \mathrm{g} / \mu \mathrm{l} \mathrm{mPLCZ}$ cRNA, as previously described (Ross et al. 2008b). Then, to prevent the extrusion of the second polar body, NTUs were cultured for $5 \mathrm{~h}$ in $\mathrm{KSOM}$ containing $7.5 \mu \mathrm{g} / \mu \mathrm{l} \mathrm{CB}$. After activation, the NTU were rinsed several times in $\mathrm{HH}$ medium and cultured in $400 \mu \mathrm{l}$ drops of KSOM medium supplemented with $3 \mathrm{mg} / \mathrm{ml}$ of BSA under mineral oil at $38.5^{\circ} \mathrm{C}$ and $5 \% \mathrm{CO}_{2}$ in air for 7 days. On day 3 (NT=day 0 ), culture medium was supplemented with $10 \%$ v/v fetal bovine serum (FBS). Eight-cell and blastocyst-stage embryos were collected 50 and $180 \mathrm{~h}$ after activation respectively.

Fertilized control embryos were produced by IVF using Tyrode's albumin lactate pyruvate-based medium (Parrish et al. 1986) and cultured under the same conditions as the SCNT embryos.

\section{Intracellular calcium monitoring}

Intracellular $\mathrm{Ca}^{2+}$ concentrations were measured using Fura Red. After PLCZ injection, the zygotes were loaded in $\mathrm{HH}$ medium containing $2 \mu \mathrm{M}$ Fura Red AM (Invitrogen), $0.02 \% \mathrm{v} / \mathrm{v}$ Pluronic F-127 (Invitrogen) and $0.5 \mathrm{M}$ sulfinpyrazone for $10 \mathrm{~min}$ at $38.5^{\circ} \mathrm{C}$. After loading, oocytes were placed in $50 \mu \mathrm{l}$ drops of protein-free $\mathrm{HH}$ medium containing $0.5 \mathrm{M}$ sulfinpyrazone on a Petri dish with a glass bottom and covered with mineral oil. During the first $5 \mathrm{~h}$ after PLCZ injection, the medium was also supplemented with $7.5 \mu \mathrm{g} / \mathrm{ml} \mathrm{CB}$. The Petri dish was placed on a heated stage on a Nikon TE2000-U microscope (Nikon, Tokio, Japan). A 120W metal halide lamp (X-Cite 120, EXFO, Quebec, Canada) provided the excitation light through fiber optics, and excitation wavelengths were 440 and $490 \mathrm{~nm}$. Wavelengths greater than $600 \mathrm{~nm}$ were collected through a 20X objective by an EMCCD camera fitted with on-chip multiplication gain (Cascade 512B, Roper Scientific, Tucson, AZ, USA). Fluorescence intensity ratios $(440 / 490 \mathrm{~nm})$ were measured every $20 \mathrm{~s}$ using Metamorph software (Universal Imaging Corp., Downingtown, PA, USA).

\section{Blastocyst differential staining and TUNEL assay}

The zona pellucida of each blastocyst was removed by incubation in $10 \mathrm{lU} / \mathrm{ml}$ pronase for $2 \mathrm{~min}$. After thoroughly rinsing the embryos in $\mathrm{HH}$ medium, they were exposed for $10 \mathrm{~s}$ to $0.2 \% \mathrm{v} / \mathrm{v}$ Triton $\mathrm{X}-100$ in PBS, Gibco) containing $2 \mathrm{mg} / \mathrm{ml}$ BSA. The embryos were then incubated for $15 \mathrm{~min}$ in PBS-BSA containing $10 \mu \mathrm{g} / \mathrm{ml}$ bisbenzimide and $30 \mu \mathrm{g} / \mathrm{ml}$ propidium iodide. After staining, the embryos were fixed in $4 \% \mathrm{w} / \mathrm{v}$ paraformaldehyde for $15 \mathrm{~min}$ and stored at $4{ }^{\circ} \mathrm{C}$, for no more than 7 days, until a TUNEL assay was performed. TUNEL assays were by the In Situ Cell Death Detection Kit (Roche Applied Science) following manufacturer instructions. Briefly, the embryos were exposed to the labeling solution containing the terminal deoxynucleotidyl transferase and fluorescein-labeled nucleotide mixture for $1 \mathrm{~h}$ at $37^{\circ} \mathrm{C}$ in a humid chamber. The embryos were then treated with RNase A $(50 \mathrm{IU} / \mathrm{ml})$ for $30 \mathrm{~min}$ at $37{ }^{\circ} \mathrm{C}$. Embryos treated with RQ1 DNase $(10 \mathrm{IU} / \mathrm{ml})$ were used as a positive control, and negative controls were incubated in labeling solution omitting the enzyme. After intensive washing in PBS-BSA, the embryos were mounted in a small drop of ProLong Gold antifade solution (Invitrogen) and evaluated under epifluorescence microscopy. TE cells were observed as red nuclei; ICM cells, as blue nuclei; and TUNELpositive cells, as green nuclei.

\section{Blastocyst chromosomal analysis}

Embryos were incubated for $12-14 \mathrm{~h}$ in KSOM-BSA plus $5 \%$ $\mathrm{v} / \mathrm{v}$ FBS containing $0.05 \mu \mathrm{g} / \mathrm{ml}$ demecolcine. Then, embryos were exposed to a hypotonic $0.075 \mathrm{M} \mathrm{KCl}$ solution for $5 \mathrm{~min}$ to induce nuclear swelling. Subsequently, embryos were placed on a clean glass slide in a small volume of media. A methanolacetic acid solution (1:1) was dropped on top of embryos while gently blowing with the slides placed under the stereoscope. Just before the solution dried, the slide was submerged in a 3:1 methanol-acetic acid solution for $1 \mathrm{~h}$ and then allowed to dry at room temperature for $24 \mathrm{~h}$. After drying, samples were mounted using Prolong Gold antifade solution with 4',6-diamidino-2-phenylindole (Invitrogen). Chromosome spreads were evaluated under epifluorescence at 1000X magnification with oil immersion optics (Nikon). Embryos were classified as being haploid, diploid, triploid, tetraploid, polyploid, and mixoploid.

\section{Cell number determination of live embryos}

The total number of cells in the blastocysts used for gene expression analysis was determined by live confocal microscopy, as previously described (Ross et al. 2006). Briefly, the nuclei were stained by incubation in $\mathrm{HH}$ medium containing $5 \mu \mathrm{M}$ SYTO 16 (Molecular Probes, Eugene, OR, USA) for $15 \mathrm{~min}$. Then, the embryos were placed with the ICM facing the objective lens between two coverslips separated from each other by $150 \mu \mathrm{m}$ and imaged using a spinning-disk confocal system (CARV, Atto Bioscience Inc., Rockville, MD, USA) mounted on a Nikon TE2000-U microscope. A Z-stack of the embryo was acquired every $5 \mu \mathrm{m}$, and the images were processed for three-dimensional deconvolution using Autoquant (Media Cybernetics, Inc., Silver Spring, MD, USA) and analyzed using Metamorph software (Universal Imaging Corp). All nuclei were marked by drawing a contour on the image for each focal plane and counted.

\section{Quantitative RT-PCR}

Groups of five eight-cell embryos and individual blastocysts were lysed in $20 \mu \mathrm{l}$ of extraction buffer, and then incubated at $42{ }^{\circ} \mathrm{C}$ for $30 \mathrm{~min}$ followed by centrifugation at $3000 \mathrm{~g}$ for $2 \mathrm{~min}$ 
and stored at $-80^{\circ} \mathrm{C}$. Before RNA extraction, each sample was spiked with $2 \mu \mathrm{l}$ of $250 \mathrm{fg} / \mu \mathrm{l} \mathrm{HcRed} 1 \mathrm{cRNA}$, used as an exogenous control (Bettegowda et al. 2006), and $50 \mu \mathrm{g}$ tRNA as a carrier. Total RNA was extracted from each sample using the PicoPure RNA Isolation Kit (Arcturus, Carlsbad, CA, USA) according to the manufacturer's instructions. Residual genomic DNA was removed by DNAse I digestion using an RNAse-Free DNAse Set (Qiagen). RNA was eluted from the purification column using $11 \mu \mathrm{l}$ nuclease-free water (Ambion). RNA was then primed with oligo-dT (Invitrogen) and converted into cDNA using Superscript II (Invitrogen) following the manufacturer's instructions. Each RT reaction was finally diluted with nuclease-free water to a final volume of $60 \mu \mathrm{l}$.

The quantification of all gene transcripts was done by realtime quantitative RT-PCR using SYBR Green PCR Master Mix (Applied Biosystems, Foster City, CA, USA). Absolute quantification using this method is described elsewhere (Li \& Wang 2000, Whelan et al. 2003). Primer sequences for all the genes are shown in Supplementary Table 1, which can be viewed online at www.reproduction-online.org/supplemental/.

Each reaction mixture consisted of $2 \mu \mathrm{l}$ cDNA, $5 \mu \mathrm{mol}$ each of forward and reverse primers, $7.5 \mu$ of nuclease-free water, and $12.5 \mu \mathrm{l}$ SYBR Green PCR Master Mix in a total reaction volume of $25 \mu$ l. Reactions were performed in duplicate for each sample in an ABI Prism 7000 Sequence Detection System (Applied Biosystems). Dissociation curves were performed after each PCR run to ensure that a single PCR product had been amplified.

The copy number of HcRed1 cRNA was determined for each sample using a standard curve constructed from the plasmid pHc-Red1-Nuc (Clontech). For HcRed, GAPDH, POU5F1, NANOG, SOX2, CDX2, and FGFR2, plasmids containing the partial cDNAs were used to construct standard curves using tenfold serial dilutions. For TRYP8, GLUT1, DSC2, and U2AF1L2, a relative standard curve was used to determine abundance in arbitrary units using serial dilutions of amplified cDNA from a pool of bovine IVF and SCNT blastocysts and fibroblasts.

For each measurement, threshold lines were adjusted to intersect amplification lines in the exponential portion of the amplification curve using the automatic setting of the thermocycler program. HcRed1 (the external control) abundance was determined in each sample and used to normalize for differences in RNA extraction and RT efficiency. Blastocyst embryo samples were further normalized to the total cell number of each individual embryo.

\section{Immunostaining of embryos}

Embryos were washed in PBS containing $1 \mathrm{mg} / \mathrm{ml}$ of polyvinyl alcohol (PVA), fixed with $4 \% \mathrm{w} / \mathrm{v}$ paraformaldehyde for $15 \mathrm{~min}$ in PBS (Gibco) and stored at $4{ }^{\circ} \mathrm{C}$ in PBS containing $1 \mathrm{mg} / \mathrm{ml}$ of PVA for no longer than 3 weeks. Embryos were permeabilized in $1 \% \mathrm{v} / \mathrm{v}$ Triton $\mathrm{X}-100$ for $30 \mathrm{~min}$ at room temperature, then incubated with Image-iT FX signal enhancer (Invitrogen) for $30 \mathrm{~min}$, and blocked with 10\% v/v normal goat serum for $2 \mathrm{~h}$. Embryos were incubated overnight at $4{ }^{\circ} \mathrm{C}$ in $1 \% \mathrm{w} / \mathrm{v}$ BSA and primary antibodies against H3K27me3; (ab6002; Abcam, Cambridge, UK) and acetylated lysine 5 of histone $\mathrm{H} 4$ (H4K5Ac; 07-327; Upstate). After $6 \mathrm{~h}$ washing in PBS containing $0.1 \% \mathrm{v} / \mathrm{v}$ Triton X-100, embryos were incubated with secondary antibodies conjugated with Alexa 488 and Alexa 594 (Invitrogen) for $1 \mathrm{~h}$ at room temperature. DNA was visualized by bisbenzimide staining. For imaging, embryos were mounted in $11 \mu \mathrm{l}$ antifade solution and compressed with a coverslip. Imaging was performed by a spinning-disk confocal system mounted on a Nikon TE-2000 microscope at $40 \times$ (numerical aperture (NA) 1.3) and $100 \times(\mathrm{NA} 1.3$ ) magnifications. Optical sections every $1 \mu \mathrm{m}$ were acquired for each embryo. Metamorph software was used for image acquisition and analysis. Fluorescence intensity determinations were performed as previously described (Ross et al. 2008a). All sections were combined by a maximum projection, and each nucleus was delineated under the blue channel (nuclear staining). Also, two different cytoplasmic areas were delineated to use as background fluorescence. The regions were then transferred to the red and green channels, and the average pixel intensity was calculated by the software for each region. For analysis, each region's fluorescence intensity was divided by the average of the two cytoplasmic regions.

\section{Statistical analysis}

Continuous response variables were analyzed by ANOVA using the MIXED procedure of SAS (Cary, NC, USA). The models included treatment as fixed effect and a random effect of manipulation day. Rates of embryonic development to cleavage and blastocyst stage were evaluated using a generalized linear model methodology, including the fixed effect of treatment and the random effect of replicate. The analyses were implemented using the GLIMMIX procedure of SAS, assuming a binomial distribution of the response variables and a logit link function.

\section{Declaration of interest}

The authors declare that there is no conflict of interest that could be perceived as prejudicing the impartiality of the research reported.

\section{Funding}

This project was supported by the Michigan State University Experiment Station, The office of the Vice President for Research and Graduate Studies and the MSU foundation to J B C and by National Research Initiative Competitive Grant no 2007-35203-17840 from USDA Cooperative State Research, Education, and Extention Sevice and by USDA/Hatch grant to $R$ A F. R A $F$ also received support from NIH/NICHD (\#1R01HD051872).

\section{Acknowledgements}

The authors are extremely grateful to Juan Pedro Steibel for assistance with statistical analysis, German Kaiser for his help with embryo production, Jason Knott for his critical comments on the manuscript, and the Cellular Reprogramming Laboratory members for their support during the course of this study. 


\section{References}

Alberio R, Zakhartchenko V, Motlik J \& Wolf E 2001 a Mammalian oocyte activation: lessons from the sperm and implications for nuclear transfer. International Journal of Developmental Biology 45 797-809.

Alberio R, Brero A, Motlik J, Cremer T, Wolf E \& Zakhartchenko V 2001b Remodeling of donor nuclei, DNA-synthesis, and ploidy of bovine cumulus cell nuclear transfer embryos: effect of activation protocol. Molecular Reproduction and Development 59 371-379.

Azuara V, Perry P, Sauer S, Spivakov M, Jorgensen HF, John RM, Gouti M, Casanova M, Warnes G, Merkenschlager M et al. 2006 Chromatin signatures of pluripotent cell lines. Nature Cell Biology 8 532-538.

Bettegowda A, Patel OV, Ireland JJ \& Smith GW 2006 Quantitative analysis of messenger RNA abundance for ribosomal protein L-15, cyclophilin-A, phosphoglycerokinase, beta-glucuronidase, glyceraldehyde 3-phosphate dehydrogenase, beta-actin, and histone $\mathrm{H} 2 \mathrm{~A}$ during bovine oocyte maturation and early embryogenesis in vitro. Molecular Reproduction and Development 73 267-278.

Beyhan Z, Ross PJ, lager AE, Kocabas AM, Cunniff K, Rosa GJ \& Cibelli JB 2007 Transcriptional reprogramming of somatic cell nuclei during preimplantation development of cloned bovine embryos. Developmental Biology 305 637-649

Bhak JS, Lee SL, Ock SA, Mohana Kumar B, Choe SY \& Rho GJ 2006 Developmental rate and ploidy of embryos produced by nuclear transfer with different activation treatments in cattle. Animal Reproduction Science 92 37-49.

Boyer LA, Plath K, Zeitlinger J, Brambrink T, Medeiros LA, Lee TI, Levine SS, Wernig M, Tajonar A, Ray MK et al. 2006 Polycomb complexes repress developmental regulators in murine embryonic stem cells. Nature 441 349-353.

Cibelli J 2007 Developmental biology. A decade of cloning mystique. Science 316 990-992.

Cibelli JB, Stice SL, Golueke PJ, Kane JJ, Jerry J, Blackwell C, Ponce de Leon FA \& Robl JM 1998 Cloned transgenic calves produced from nonquiescent fetal fibroblasts. Science 280 1256-1258.

Cibelli JB, Kocabas AM, Beyhan Z \& Ross PJ 2006 Cellular reprogramming for the creation of patient-specific embryonic stem cells. Stem Cell Reviews 2 289-295.

Ducibella T, Huneau D, Angelichio E, Xu Z, Schultz RM, Kopf GS, Fissore R, Madoux S \& Ozil JP 2002 Egg-to-embryo transition is driven by differential responses to $\mathrm{Ca}(2+)$ oscillation number. Developmental Biology 250 280-291.

Ducibella T, Schultz RM \& Ozil JP 2006 Role of calcium signals in early development. Seminars in Cell and Developmental Biology 17 324-332.

Fissore RA, Dobrinsky JR, Balise JJ, Duby RT \& Robl JM 1992 Patterns of intracellular $\mathrm{Ca}^{2+}$ concentrations in fertilized bovine eggs. Biology of Reproduction 47 960-969.

Gao S, Chung YG, Williams JW, Riley J, Moley K \& Latham KE 2003 Somatic cell-like features of cloned mouse embryos prepared with cultured myoblast nuclei. Biology of Reproduction 69 48-56.

Heyman Y, Chavatte-Palmer P, LeBourhis D, Camous S, Vignon X \& Renard JP 2002 Frequency and occurrence of late-gestation losses from cattle cloned embryos. Biology of Reproduction 66 6-13.

Hochedlinger K \& Jaenisch R 2006 Nuclear reprogramming and pluripotency. Nature 441 1061-1067.

Kane MT 2003 A review of in vitro gamete maturation and embryo culture and potential impact on future animal biotechnology. Animal Reproduction Science 79 171-190.

Knott JG, Kurokawa M, Fissore RA, Schultz RM \& Williams CJ 2005 Transgenic RNA interference reveals role for mouse sperm phospholipase Czeta in triggering $\mathrm{Ca}^{2+}$ oscillations during fertilization. Biology of Reproduction 72 992-996.

Koo D-B, Kang Y-K, Choi Y-H, Park JS, Kim H-N, Oh KB, Son D-S, Park H, Lee K-K \& Han Y-M 2002 Aberrant allocations of inner cell mass and trophectoderm cells in bovine nuclear transfer blastocysts. Biology of Reproduction 67 487-492.

Kouchi Z, Fukami K, Shikano T, Oda S, Nakamura Y, Takenawa T \& Miyazaki S 2004 Recombinant phospholipase Czeta has high $\mathrm{Ca}^{2+}$ sensitivity and induces $\mathrm{Ca}^{2+}$ oscillations in mouse eggs. Journal of Biological Chemistry 279 10408-10412.

Krawetz SA 2005 Paternal contribution: new insights and future challenges. Nature Reviews. Genetics 6 633-642.
Kurokawa M, Sato K \& Fissore RA 2004 Mammalian fertilization: from sperm factor to phospholipase Czeta. Biology of the Cell 96 37-45.

Latham KE 2004 Cloning: questions answered and unsolved. Differentiation 72 11-22.

Latham KE 2005 Early and delayed aspects of nuclear reprogramming during cloning. Biology of the Cell 97 119-132.

Lee $\mathrm{TI}$, Jenner RG, Boyer LA, Guenther MG, Levine SS, Kumar RM, Chevalier B, Johnstone SE, Cole MF, Isono K et al. 2006 Control of developmental regulators by polycomb in human embryonic stem cells. Cell 125 301-313.

Li X \& Wang X 2000 Application of real-time polymerase chain reaction for the quantitation of interleukin-1 beta mRNA upregulation in brain ischemic tolerance. Brain Research. Brain Research Protocols 5 211-217.

Machaty Z 2006 Activation of oocytes after nuclear transfer. Methods in Molecular Biology 348 43-58.

Malcuit C \& Fissore RA 2007 Activation of fertilized and nuclear transfer eggs. Advances in Experimental Medicine and Biology 591 117-131.

Malcuit C, Kurokawa M \& Fissore RA 2006a Calcium oscillations and mammalian egg activation. Journal of Cellular Physiology 206 565-573.

Malcuit C, Maserati M, Takahashi Y, Page R \& Fissore RA 2006b Intracytoplasmic sperm injection in the bovine induces abnormal $\left[\mathrm{Ca}^{2+}\right]_{\mathrm{i}}$ responses and oocyte activation. Reproduction, Fertility, and Development 18 39-51.

Nakada K, Mizuno J, Shiraishi K, Endo K \& Miyazaki S 1995 Initiation, persistance, and cessation of the series of intracellular $\mathrm{Ca}^{2+}$ responses during fertilization of bovine eggs. Journal of Reproduction and Development 41 77-84.

Ostermeier GC, Miller D, Huntriss JD, Diamond MP \& Krawetz SA 2004 Reproductive biology: delivering spermatozoan RNA to the oocyte. Nature 429154.

Ozil JP \& Huneau D 2001 Activation of rabbit oocytes: the impact of the $\mathrm{Ca}^{2+}$ signal regime on development. Development 128 917-928.

Ozil JP, Markoulaki S, Toth S, Matson S, Banrezes B, Knott JG, Schultz RM, Huneau D \& Ducibella T 2005 Egg activation events are regulated by the duration of a sustained [Ca2 + ]cyt signal in the mouse. Developmental Biology 282 39-54.

Ozil JP, Banrezes B, Toth S, Pan H \& Schultz RM $2006 \mathrm{Ca}^{2+}$ oscillatory pattern in fertilized mouse eggs affects gene expression and development to term. Developmental Biology 300 534-544.

Parrish JJ, Susko-Parrish JL, Leibfried-Rutledge ML, Critser ES, Eyestone WH \& First NL 1986 Bovine in vitro fertilization with frozen-thawed semen. Theriogenology 25 591-600.

Reik W, Dean W \& Walter J 2001 Epigenetic reprogramming in mammalian development. Science 293 1089-1093.

Renard JP, Maruotti J, Jouneau A \& Vignon X 2007 Nuclear reprogramming and pluripotency of embryonic cells: application to the isolation of embryonic stem cells in farm animals. Theriogenology 68 S196-S205.

Rideout WM III, Eggan K \& Jaenisch R 2001 Nuclear cloning and epigenetic reprogramming of the genome. Science 293 1093-1098.

Rogers NT, Hobson E, Pickering S, Lai FA, Braude P \& Swann K 2004 Phospholipase Czeta causes $\mathrm{Ca}^{2+}$ oscillations and parthenogenetic activation of human oocytes. Reproduction 128 697-702.

Rogers NT, Halet G, Piao Y, Carroll J, Ko MS \& Swann K 2006 The absence of a $\mathrm{Ca}(2+)$ signal during mouse egg activation can affect parthenogenetic preimplantation development, gene expression patterns, and blastocyst quality. Reproduction 132 45-57.

Ross PJ, Perez GI, Ko T, Yoo MS \& Cibelli JB 2006 Full developmental potential of mammalian preimplantation embryos is maintained after imaging using a spinning-disk confocal microscope. BioTechniques $\mathbf{4 1}$ 741-750.

Ross PJ, Ragina NP, Rodriguez RM, lager AE, Siripattarapravat K, LopezCorrales N \& Cibelli JB 2008a Polycomb gene expression and histone H3 lysine 27 trimethylation changes during bovine preimplantation development. Reproduction 136 777-785.

Ross PJ, Beyhan Z, lager AE, Yoon SY, Malcuit C, Schellander K, Fissore RA \& Cibelli JB 2008b Parthenogenetic activation of bovine oocytes using bovine and murine phospholipase C zeta. BMC Developmental Biology 816.

Saunders CM, Larman MG, Parrington J, Cox LJ, Royse J, Blayney LM, Swann K \& Lai FA 2002 PLC zeta: a sperm-specific trigger of $\mathrm{Ca}(2+)$ oscillations in eggs and embryo development. Development 129 3533-3544. 
Schuettengruber B, Chourrout D, Vervoort M, Leblanc B \& Cavalli G 2007 Genome regulation by polycomb and trithorax proteins. Cell 128 735-745. Seshagiri P \& Bavister B 1989 Phosphate is required for inhibition by glucose of development of hamster 8-cell embryos in vitro. Biology of Reproduction 40 607-614.

Shi W, Zakhartchenko V \& Wolf E 2003 Epigenetic reprogramming in mammalian nuclear transfer. Differentiation 71 91-113.

van Soom A, Ysebaert MT \& de Kruif A 1997 Relationship between timing of development, morula morphology, and cell allocation to inner cell mass and trophectoderm in in vitro-produced bovine embryos. Molecular Reproduction and Development 47 47-56.

Van Soom A, Vanroose G \& de Kruif A 2001 Blastocyst evaluation by means of differential staining: a practical approach. Reproduction in Domestic Animals 36 29-35.

Swann K, Larman MG, Saunders CM \& Lai FA 2004 The cytosolic sperm factor that triggers $\mathrm{Ca}^{2+}$ oscillations and egg activation in mammals is a novel phospholipase C: PLCzeta. Reproduction 127 431-439.

Swann K, Saunders CM, Rogers NT \& Lai FA 2006 PLCzeta(zeta): a sperm protein that triggers $\mathrm{Ca}^{2+}$ oscillations and egg activation in mammals. Seminars in Cell and Developmental Biology 17 264-273.

Van De Velde A, Liu L, Bols PE, Ysebaert MT \& Yang X 1999 Cell allocation and chromosomal complement of parthenogenetic and IVF bovine embryos. Molecular Reproduction and Development 54 57-62.

Whelan JA, Russell NB \& Whelan MA 2003 A method for the absolute quantification of cDNA using real-time PCR. Journal of Immunological Methods 278 261-269.
Wilmut I, Beaujean N, de Sousa PA, Dinnyes A, King TJ, Paterson LA, Wells DN \& Young LE 2002 Somatic cell nuclear transfer. Nature 419 583-587.

Winger QA, De La Fuente R, King WA, Armstrong DT \& Watson AJ 1997 Bovine parthenogenesis is characterized by abnormal chromosomal complements: implications for maternal and paternal co-dependence during early bovine development. Developmental Genetics 21 160-166.

Wu AT, Sutovsky P, Manandhar G, Xu W, Katayama M, Day BN, Park KW, Yi YJ, Xi YW, Prather RS et al. 2007 PAWP, a sperm-specific WW domain-binding protein, promotes meiotic resumption and pronuclear development during fertilization. Journal of Biological Chemistry 282 12164-12175

Yoneda A, Kashima M, Yoshida S, Terada K, Nakagawa S, Sakamoto A, Hayakawa K, Suzuki K, Ueda J \& Watanabe T 2006 Molecular cloning, testicular postnatal expression, and oocyte-activating potential of porcine phospholipase Czeta. Reproduction 132 393-401.

Zakhartchenko V, Durcova-Hills G, Stojkovic M, Schernthaner W, Prelle K, Steinborn R, Muller M, Brem G \& Wolf E 1999 Effects of serum starvation and re-cloning on the efficiency of nuclear transfer using bovine fetal fibroblasts. Journal of Reproduction and Fertility 115 325-331.

Received 2 October 2008

First decision 21 November 2008

Accepted 11 December 2008 